THE purpose of this study was the effect of epith elium damage on mechanical responses of airway smooth muscles under different resting tension. We performed acetylcholine ( $\mathrm{ACh})\left(10^{-5} \mathrm{M}\right)$-in duced con traction on tracheal strips from 30 rabbits in five groups $(0.5,1,1.5,2$ and $2.5 \mathrm{~g})$ before and after epithelium removal. At low resting tension $(0.5-1.5 \mathrm{~g})$, the epithelium removal decreased the $A C h$-induced contractions. At $2 \mathrm{~g}$ resting tension, the epithelium removal increased the ACh-induced contractions of airways with in tact epithelium about $20 \%$. At $2.5 \mathrm{~g}$ resting tension, the elevation of contraction is about $25 \%$ $(P<0.01)$. Consequently, after epithelium loss, the resting tension determines the airway smooth muscles responsiveness. In asthma, mediators such as ACh act on already contracted in flam matory airways, which results in additional increase of contraction. In contrast, low resting tension, a condition that simulates normal tidal breathing, protects from bronchoconstriction even when the epithelium is damaged.

Key words: Epithelium, Airways, Smooth muscle pathophysiology, Bronchial asthma

\section{Airway responsiveness: role of inflammation, epithelium damage and smooth muscle tension}

\section{K. I. Gourgoulianis ${ }^{\text {CA }}$, A. Domali and P. A. Molyvdas}

Department of Physiology, Medical School, University of Thessaly, Greece

\author{
${ }^{\mathrm{CA}}$ Corresponding Author \\ Present Address: 22 Papakiriazi, 41222 Larissa, Greece \\ Tel: $(+41) 532501$ \\ Fax: (+41) 255420 \\ Email: kgourg@med.uth.gr
}

\section{Introduction}

The effects of lung-volume changes on airw ay tones can be mimicked in isolated bronchial segments in vitro, in which inflation-deflation cycles decrease the transmural pressure of contracted bronchi. ${ }^{1}$ Studies with preparations of bronchial smooth muscles have been presented in the literature. A large range of resting tensions $(0.5-2.5 \mathrm{~g})$ was used in these experiments. ${ }^{2}$ Resting tension determines the responsiveness of airway smooth muscles to contractile and relaxant agents. In normal human subjects, deep inspiration decreases airway resistance. ${ }^{3}$ Fish et al. suggested that the major problem in asthma might be an impairment in the ability of inspiration to stretch the airway smooth muscle. ${ }^{4}$ Cyclic stretch of airway epithelium also plays a key role in regulating inflammatory airw ay diseases including bronchial asthma, in which airw ay mechanics are altered. ${ }^{5}$

In this study, we evaluated the properties of airw ay smooth muscle under different resting tensions. First, we recorded the mechanical responses of smooth muscles during contraction with acetylcholine (ACh) and, second, we removed epithelium and AChinduced contractions in a range of resting tension were also recorded.

\section{Materials and methods}

Portions of tracheas were obtained from 30 rabbits (1-2 kg body weight) that have been previously anaesthetized with pentothal (dose, $20 \mathrm{mg} / \mathrm{kg}$ intravenously, slowly). After immediate excision, the tracheas were placed in Krebs buffer $\left(\mathrm{pH} 7.4,37^{\circ} \mathrm{C}\right)$ with the following composition: $\mathrm{Na}^{+}, 137 \mathrm{mM} ; \mathrm{Mg}^{2+}$, $1.1 \mathrm{mM} ; \mathrm{K}^{+}, 5.9 \mathrm{mM} ; \mathrm{Ca}^{2+}, 2.0 \mathrm{mM} ; \mathrm{Cl}^{-}, 123.0 \mathrm{mM}$; $\mathrm{H}_{2} \mathrm{PO}_{4}^{-}, 1.2 \mathrm{mM} ; \mathrm{HCO}_{3}^{-}, 24.9 \mathrm{mM}$; glucose, $9.6 \mathrm{mM}$. The solution was gassed with $95 \% \mathrm{O}_{2}$ and $5 \% \mathrm{CO}_{2}$. Muscle strips $(2-3 \mathrm{~mm})$ taken from the tracheas were superfused under $1 \mathrm{~g}$ of tension, in a bathing chamber that was continuously perfused with Krebs solution. Changes in tension were recorded on a Grass FT03C force displacement transducer and displayed on a Universal oscilograph (Harvard) recorder.

A single bolus dose of $0.2-0.5 \mathrm{ml}$ of $10^{-1} \mathrm{MACh}$ w as given to each muscle strip, to induce contraction. The preparation was then washed repeatedly and left until tension had returned to baseline. Each muscle strip was equilibrated at a resting load $(1 \mathrm{~g})$ for at least 60 min before starting the experiment.

We used ACh $\left(10^{-5} \mathrm{M}\right)$ to induce contractions at different resting tensions $(0.5,1,1.5,2$ and $2.5 \mathrm{~g})$. Each muscle strip in the same resting tension was contracted by ACh before and after epithelium removal. Experiments from six rabbits were performed for each resting tension. Epithelium was removed mechanically. ACh was purchased from Sigma.

\section{Results}

Figure 1 shows that epithelium removal increases the ACh-induced contraction at high resting tension. At 


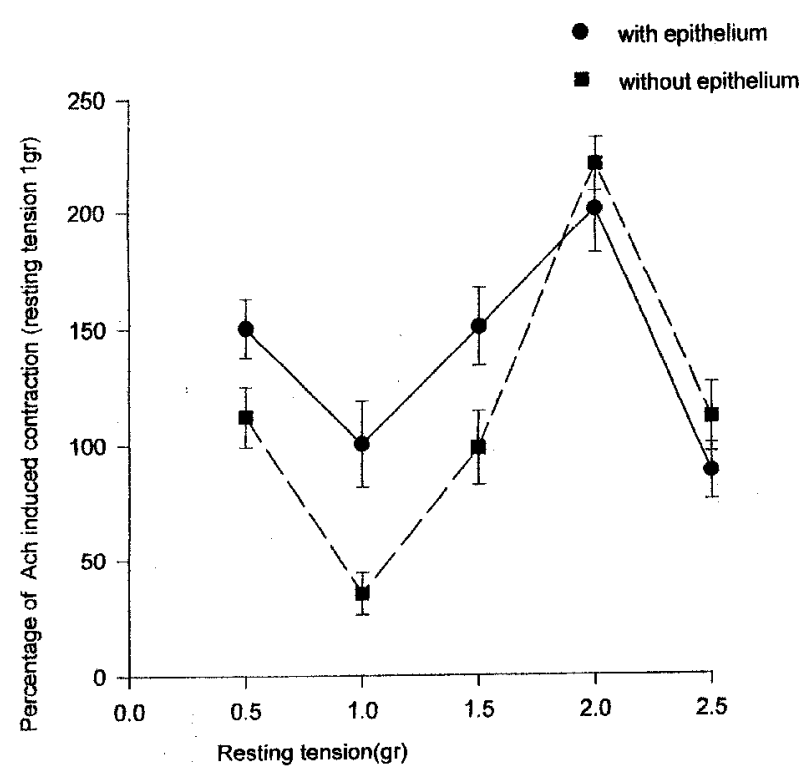

FIG. 1. Ach-induced contractions on different resting tensions.

$2.5 \mathrm{~g}$ resting tension, the increase of contraction is $24.45 \%(P<0.04)$. At low resting tension, under $1.5 \mathrm{~g}$, the epithelium removal decreases the ACh-induced contractions. The highest decrease was recorded at $1 \mathrm{~g}$ resting tension $(72.30 \%)(P<0.01)$.

\section{Discussion}

Our results showed that resting tension alters airway smooth muscle hyper-responsiveness. Epithelium removal increases airw ay smooth muscle contraction only in high resting tension. The influence of low resting tension on epithelial damage has a protective effect on airw ays muscle contraction.

In our experiments, ACh induces different contractions on different airway smooth muscle resting tension. Recent articles showed that tension applied to airw ay smooth muscles at the start of an isometric in vitro experiment is an important factor that determines responsiveness. ${ }^{6,7}$ Airw ay epithelium also moderates the responsiveness of underlying smooth muscles. Hyper-reactivity of the airways is associated with damage of the epithelium. ${ }^{8}$

Intact epithelium has a protective effect because it releases relaxant substances such as prostanoids and nitric oxide.' Bronchial asthma is characterized by epithelium damage and airway smooth muscle contraction. Further contraction, induced by released mediators, depends on the presented findings. Endothelin-1, a 21-amino-acid peptide that has been identified in tracheal epithelial cells, has a dual action on guinea-pig is olated trachea. It evokes contractions at low resting tone, whereas it induces relaxations at higher resting.
Resting tension seems to influence the magnitude of non-adrenergic non-cholinergic (NANC) responses. Nitric oxide is produced in the airways, mainly from epithelium, and is the main mediator of the NANC system. ${ }^{10}$ Airway epithelial cells metabolize arachidonic acid to biologically active eicosanoids, which contribute to regulation of airway smooth muscle tone. ${ }^{8}$ Cyclic stre tch of airw ays causes rapid inhibition of prostanoid synthesis. ${ }^{5}$ All these data may have important implications for the pathogenesis of as thma, in which airw ay mechanics are altered. In our study, the resting tension affect the magnitude of contraction in the loss of epithelium. When the resting tension is low (normal condition), the damage of epithelium seems to induce additional relaxation. When the resting tension is high (bronchoconstriction, such as an asthma attack), the damage of epithelium increases the airw ays smooth muscle contraction.

A few years ago, Skloot et al. showed that airw ay hyper-responsiveness in asthma is a problem of 'limited smooth muscle relax ation' with inspiration. ${ }^{11}$ This observation is based on the speculation of Green and Mead that in patients with asthma, maximal inspiration is unable to dilate the airways completely. ${ }^{12}$ It is well known that maximal inspiration elevates the airway resting tension. The interaction between high resting tension and damage of epithelium which happen in asthma attack seem to be the real cause for 'limited smooth muscle relaxation'.

In normal humans subjected to bronchoconstrictions, deep inspiration decreases airway resistance and increases expiratory flow. ${ }^{13}$ Normal tidal breathing also plays an important role in limiting airway responsiveness.

Lung-volume changes have an important effect on airw ay tone and the airw ay response to bronchoconstric tors. ${ }^{14}$ Airw ay smooth muscle undergoes constant stretch and relaxation during the respiratory cycle. The responses of airways to a variety of stimuli are modulated by the epithelium. ${ }^{15,16}$ In bronchial asthma, all the normal mechanisms are impaired. Additionally, an asthmatic airw ay has increased thickness of the smooth muscle layer, collagen deposition beneath the basement membrane and, especially, variable inflammatory products in the wall. ${ }^{17,18}$

In conclusion, mediators of asthma, such as acetylcholine, induce more contraction when acting on already contracted airways with epithelium damage, a condition mimicking asthma attack. ${ }^{19}$ Despite this vicious circle of asthmatic airway, in physiologic conditions, normal tidal breathing protect from bronchoconstriction even when the epithelium is damaged.

\section{References}

1. Shen X, Wu MF, Tepper RS, Gunst S. Mechanisms for the mechanical response of airway smooth muscle to length oscillation. J Appl Physiol 1997; 83: 731-738 
2. Filep JG, Battistini B, Sirois P. Induction by endothelin-1 of epitheliumdependent relaxation of guinea-pig trachea in vitro: role for nitric oxide. Br J Pharmacol 1993; 109: 637-644.

3. Tepper RS, Shen X, Bakan E, Gunst SJ. Maximal airway response in mature and immature rabbits during tidal ventilation. $J$ Appl Physiol 1995; 79: 1190-1198.

4. Fish JE, Ankin MG, Kelly JF, Peterman VI. Regulation of bronchomotor tone by lung inflation in asthmatic and non asthmatic subjects. $J$ Appl Physiol Respir Environ Exercise Physiol 1981; 50: 1079-1086.

5. Savla U, Sporn PHS, Waters CM. Cyclic stretch of airway epithelim inhibits prostanoid synthesis. Am J Physiol 1997; 273: L1013-L1019.

6. Watson N, Magnussen H, Rade KF. The relevance of resting tension to responsiveness and inherent tone of human bronchial smooth muscle. Br J Pharmacol 1998; 123: 694-700.

7. Watson N, Magnussen H, Rabe KF. The influence of resting tension on inherent tone and responsiveness of human bronchial smooth muscle in vitro. Am J Respir Crit Care Med 1996; 153: A742.

8. Raeburn D. Eicosanoids, epithelium and airway reactivity. Gen Pharmacol 1990; 21: 11-16.

9. Gourgoulianis KI, Iliothromitis Z, Hatziefthimiou A, Molyvdas PA. Epithelium-dependent regulation of airways smooth muscle function. A histamine nitric oxide pathway. Mediat Inflamm 1998; 7: 409-411.

10. Ward J, Belvisi Mg, Fox AJ, Miura M, Tadjkarimi S, Yacoub MH, Barnes PJ. Modulation of cholinergic neural bronchonstriction by endogenous nitric oxide and vasoactive intestinal peptide in human airway in vitro. $J$ Clin Invest 1993; 92: 736-742.
11. Scloot G, Permutt S, Togias A. Airway hyperresponsiveness in asthma: a problem of limited smooth muscle relaxation with inspiration. J Clin Invest 1995; 96: 2393-2403.

12. Green M, Mead J. Time dependence of flow-volume curves. J Appl Physiol 1974; 37: 793-797.

13. Shen X, Gunst SJ, Tepper RS. Effects of tidal volume and frequency on airway responsiveness in mechanically ventilated rabbits. J Appl Physiol 1997; 83: 1202-1208.

14. Fredberg JJ, Inouye D, Miller B et al. Airway smooth muscle, tidal stretches and dynamically determined contractile states. Am J Respir Crit Care Med 1997; 156: 1752-1759.

15. Gao Y, Vanhoutte PM. Responsiveness of the guinea pig trachea to stretch: role of the epithelium and cyclsoxygenase products. $J$ App Physiol 1993; 75: 2112-2116.

16. Shioya T, Munoz NM, Leff AR. Effect of resting smooth muscle length on contractile response in resistance airways. J Appl Physiol 1987; 62: 711-717.

17. Smith PG, Janiga KE, Bruce M. Strain incre ases airw ay smooth muscle cell proliferation. Am J Respir Cell Mol Biol 1994; 10: 85-90.

18. Adler A, Cowley AE, Bates JHT, Eidelman DH. Airway-parenchymal interdependence after airway contraction in rat lung explants. $J A p p l$ Physiol 1998; 85: 231-237.

19. Gourgoulianis KI, Molyvdas PA. Histamine-induced ventilation distribution:epithelial factors or NO? J Appl Physiol 1998; 85: 1198.

\section{Received 4 August 1999; \\ accepted 24 August 1999}




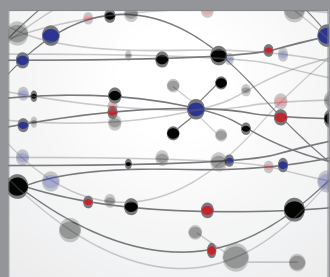

The Scientific World Journal
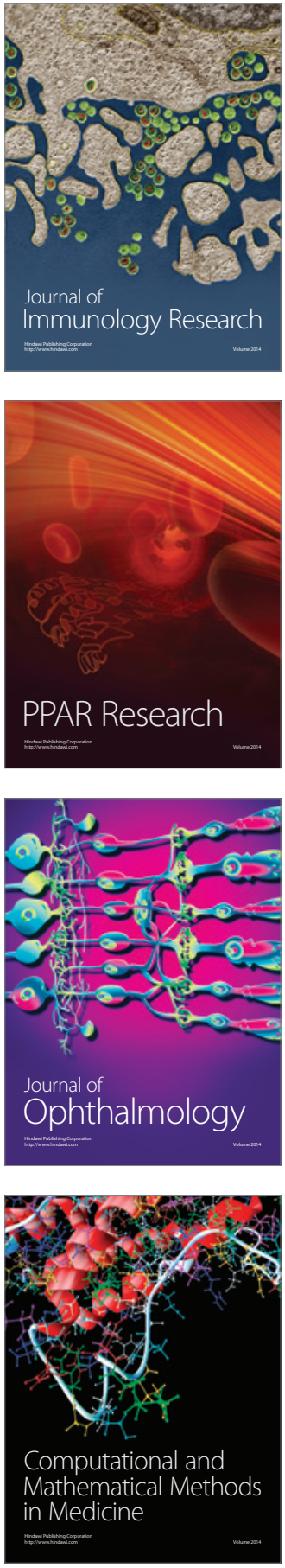

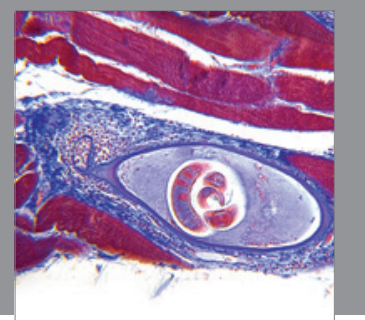

Gastroenterology

Research and Practice
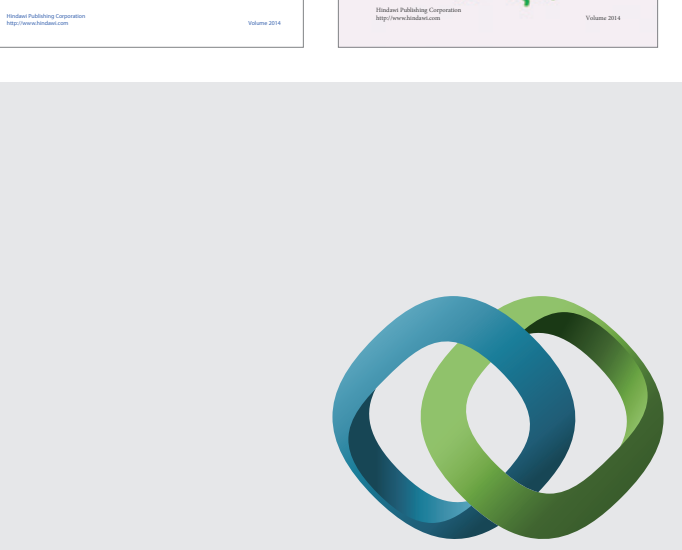

\section{Hindawi}

Submit your manuscripts at

http://www.hindawi.com
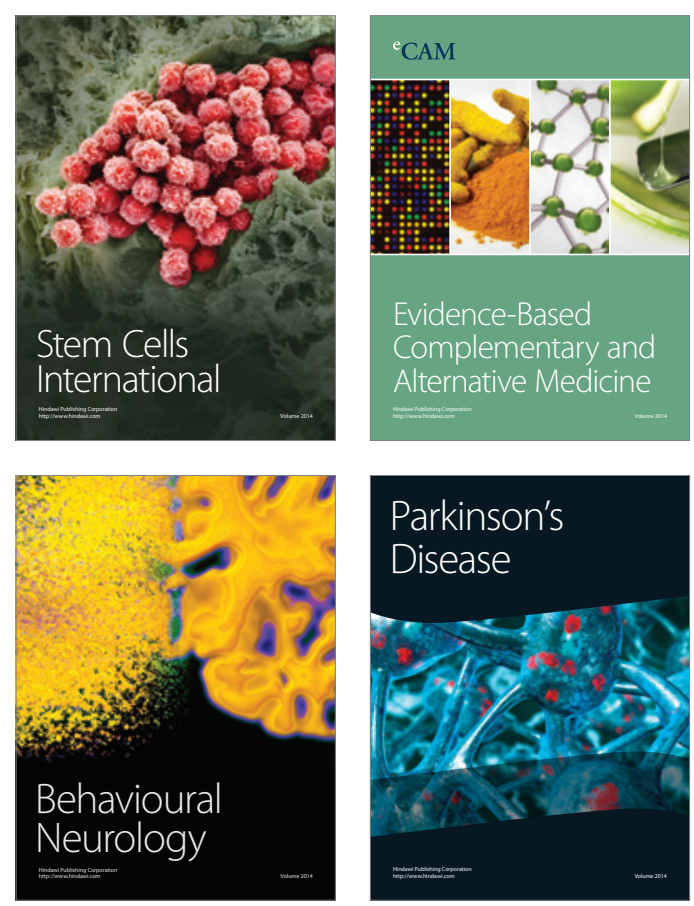

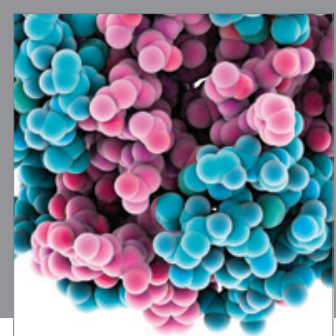

Journal of
Diabetes Research

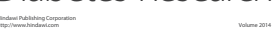

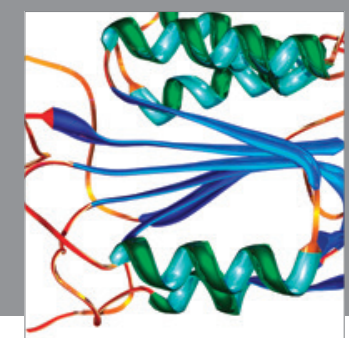

Disease Markers
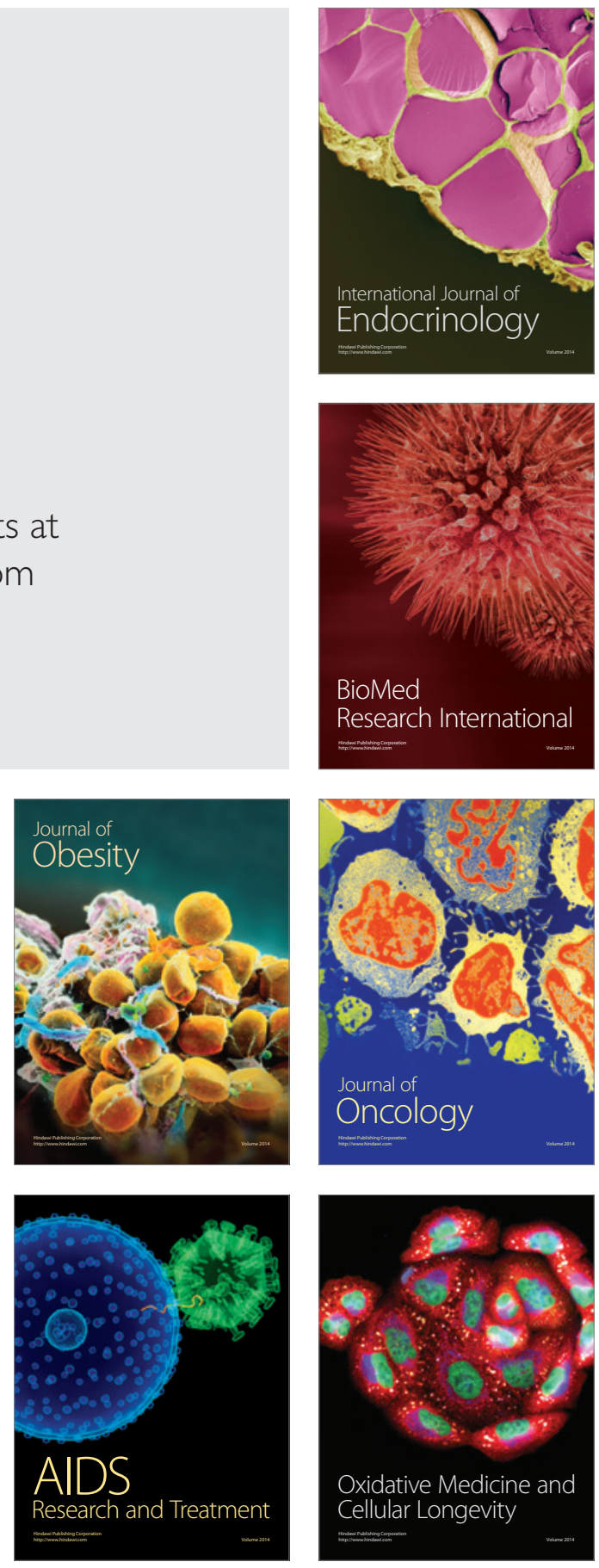